\title{
A molecular analysis of doublesex, a bifunctional gene that controls both male and female sexual differentiation in Drosophila melanogaster
}

\author{
Bruce S. Baker ${ }^{1}$ and Mariana F. Wolfner ${ }^{2}$ \\ Department of Biology, University of California, San Diego, La Jolla, California 92093 USA
}

The doublesex (dsx) gene regulates somatic sexual differentiation in both sexes in Drosophila melanogaster. $d s x$ has active but opposite negative regulatory functions in males and females. In males, the $d s x$ locus represses the genes responsible for female sexual differentiation; male differentiation functions, not being repressed, are expressed. Conversely, in females, the $d s x$ locus represses the genes involved in male sexual differentiation and the female sexual differentiation functions, not being repressed, are expressed. We have molecularly cloned the $d_{s x}$ locus by chromosomal walking and localized the gene within the cloned region by determining the positions of breakpoints of chromosomal rearrangements broken in $d s x$ and in closely flanking regions. The $d s x$ locus is about $40 \mathrm{~kb}$ in size. Its DNA is unique and appears to be organized in the same way in genomes of males and females. There is a developmentally and sexually regulated set of transcripts produced by the $d s x$ locus. During the larval period, two sex-nonspecific $d s x$ transcripts are produced. At the end of the larval period, these transcripts disappear and are replaced by a set of male-specific and female-specific transcripts. In adults, an additional male-specific transcript appears. Because genetic analysis has shown that transcription of the $d s x$ locas must occur during the pupal period for proper sexual differentiation, we infer that the sex-specific transcripts seen during the pupal period correspond to the sex determination regulatory functions defined by mutational analysis. The regulation of $d s x$ expression and possible roles of the other $d s x$ transcripts are discussed.

[Key Words: Sex determination; Drosophila; regulatory gene]

Received November 16, 1987; revised version accepted February 16, 1988.

Sexual differentiation is a particularly fascinating developmental process because it mediates the choice between two alternative development fates of a wide array of tissue and cell types. In the three organisms, Saccharomyces cerevisiae (for review, see Nasmyth 1982), Caenorhabditis elegans (for review, see Hodgkin et al. 1985), and Drosophila melanogaster (for reviews, see Baker and Belote 1983; Cline 1985; Baker et al. 1987), in which sex determination regulatory genes have been studied in great detail, it is clear that these regulatory genes act in a single hierarchy to control all aspects of somatic sexual differentiation.

In Drosophila, both sex determination and $\mathrm{X}$ chromosome transcription rate (dosage compensation) in the soma are initially determined during embryogenesis by the ratio of the number of $X$ chromosomes to sets of autosomes (the $\mathrm{X}: \mathrm{A}$ ratio) and are independent of the $\mathrm{Y}$ chromosome (Bridges 1921; Maroni and Plaut 1973; Baker and Belote 1983; Sanchez and Nöthiger 1983). In

'Current address: Department of Biological Sciences, Stanford University, Stanford, California 94305 USA.

${ }^{2}$ Current address: Section of Genetics and Development, Cornell University, Ithaca, New York 14853 USA. flies, each cell generally determines its own sex (but see Lawrence and Johnson 1986); there are no known hormonal components to sex determination. The result of the assessment of the $\mathrm{X}$ : A ratio is transduced by a set of regulatory genes (for reviews, see Baker and Belote 1983; Cline 1985; Nöthiger and Steinmann-Zwicky 1985; Baker et al. 1987) to both the genes throughout the genome whose products are responsible for generating the somatic sexual dimorphisms of the adult and to the $\mathrm{X}$ chromosomal genes whose activites are dosage compensated.

The structure of the regulatory cascade that controls somatic sex determination and dosage compensation can be understood most easily from the standpoint of the hypothesis that in males the assessment of the $\mathrm{X}: \mathrm{A}$ ratio does not generate an active signal and the regulatory genes downstream of the X:A ratio are consequently expressed in their default states (Fig. 1; Baker et al. 1987). Expression in a default state does not mean that all of these regulatory genes are inactive in males (some are active) but, rather, that their expression is due solely to the functioning of the general cellular transcriptional and translational machinery and not to any 


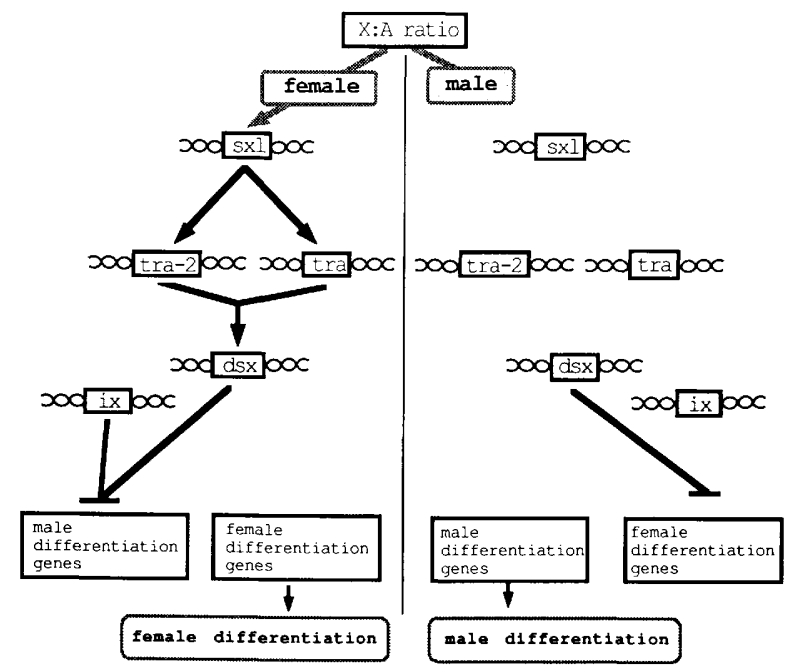

Figure 1. Regulation of sexual differentiation. Schematic representation of the regulatory hierarchy controlling somatic sexual differentiation in Drosophila. For reviews of the events prior to the activation of Sxl, see Cline (1985) and Baker and Belote (1983). Arrows between genes denote positive control. A bar at the end of a line indicates negative control. Absence of a line from a gene indicates that the gene is nonfunctional in this genotype.

sex-specific controls. In females, on the other hand, the assessment of the $\mathrm{X}$ : A ratio produces a signal that results in the expression of sex determination regulatory genes in their female (nondefault) state.

In males, only one gene is known that functions to regulate sexual differentiation (Fig. 1). This gene, doublesex $(d s x)$, is a key branchpoint in the regulatory pathway in that it has active, but opposite, functions in males and females (Baker and Ridge 1980). In males, the $d s x$ locus represses the expression of the downstream genes that are needed for female sexual differentiation. Downstream genes involved in male differentiation, not being repressed, are expressed. No functions are known that are necessary only in males for the expression of $d s x$. This has led to the notion that the expression of the male $d s x^{+}$function is the default form of expression of this gene: Unless there is an active signal to the contrary, $d s x$ will simply be expressed in this manner.

In females, one of the initial consequences of the assessment of an X : A ratio of 1 is the activation of the $S x l$ locus (Fig. 1; Cline 1978). [For recent work on events prior to the activation Sxl, see Cline $(1985,1986)$; Steinmann-Zwicky and Nöthiger (1985)]. The Sxl+ function is necessary in females for somatic sexual differentiation, germ-line function, and the female transcriptional level of X-linked genes (Cline 1978, 1984, 1986; Lucchesi and Skripsky 1981; Sanchez and Nöthiger 1982; Schüpback 1985). The $S x 1$ gene is believed to regulate sexual differentiation in somatic cells by activating two other regulatory genes, transformer (tra) and transformer-2 (tra-2). The tra ${ }^{+}$and tra- $^{+}{ }^{+}$gene products act, in turn, to bring about the expression of the $d s x^{+}$female function and, thus, repression of the $d s x^{+}$male func- tion. The $d s x^{+}$female function in conjunction with the product of another female-specific regulatory gene, intersex (ix), represses male sexual differentiation (Baker and Ridge 1980). Because the downstream genes responsible for female differentiation are not repressed by these regulatory products, they are expressed.

The functions of the sex determination regulatory genes are analogous to the homeotic genes such as those in the Bithorax (Lewis 1978) and Antennapedia (Kaufman et al. 1980) gene complexes in that they act within the context of a preestablished body plan to direct cells into alternative final states of differentiation. For nearly all of these genes, it appears that the occurrence of one or the other type of differentiation is simply determined by whether the gene is active or inactive in a given cell population (e.g., Garcia-Bellido 1977; Lewis 1978). In this context, the $d s x$ gene is unusual as it has two different active states that lead alternatively to male or female differentiation. Here we report the molecular isolation and initial characterization of the $d s x$ locus. The results suggest a molecular basis for the male-specific and female-specific functions of the $d s x$ locus, in that different processed RNAs are formed in the two sexes.

\section{Results}

Walking to dsx

To identify the salivary chromosome map location of the $d s x$ locus, we generated a number of chromosomal rearrangements with breakpoints in and near the $d s x$ gene (B.S. Baker, G. Hoff, T.C. Kaufman, and T. Hazelrigg, in prep.). Cytological analysis of these rearrangements localized $d s x$ to salivary gland chromosome band 84E1-2. A concomitant mutagenesis experiment designed to detect lethal and visible mutations in a 30 salivary chromosome band region around 84E1-2 yielded over 60 mutants that were deficiency mapped and placed into complementation groups. This provided no evidence that the $d s x$ locus was part of a gene complex controlling sexual differentiation and showed that it was closely flanked by essential genes with no apparent roles in sex determination. These experiments provided us with a set of deletions, inversions, and translocations that were integral to cloning and identifying the sequences corresponding to the $d s x$ locus. The cytological locations of rearrangements that we used in the molecular isolation of the $d s x$ locus are depicted in Figure 2. To clone the $d s x$ locus, we took advantage of a deletion, $\mathrm{Df}(3 \mathrm{R}) d s x^{M+R 2}$, that extends from within the $d s x$ locus proximally to within salivary gland chromosome band $84 \mathrm{Cl}-2$. The proximal breakpoint of this deficiency is just distal to an $\alpha$-tubulin gene in salivary gland chromosome region 84B4-6 (Mischke and Pardue 1982). Hence, a chromosomal walk (Bender et al. 1983) from the $\alpha$-tubulin gene to the proximal breakpoint of $D f(3 R) d s x^{M+R 2}$ would enable us to isolate the fusion fragment containing $d s x$ DNA from the $D f(3 R) d s x^{M+R 2}$ stock.

Because the orientation of the $\alpha$-tubulin gene clone relative to the chromosome was unknown, a bidirec- 


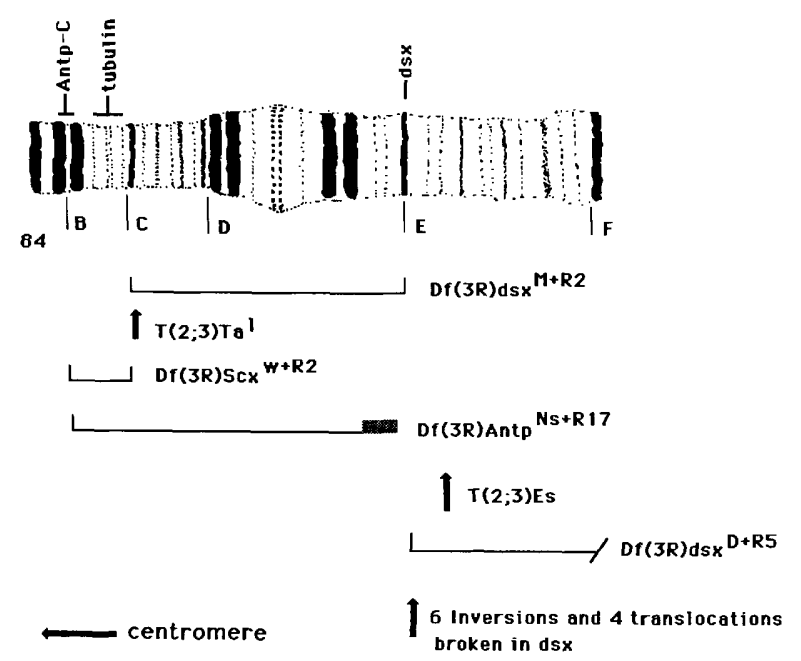

Figure 2. The salivary chromosome region around $d s x$. A drawing of a portion of salivary region 84 , with the cytological positions of the chromosomal rearrangements used to clone and molecularly characterize the $d s x$ locus. Information is from a cytogenetic characterization of the region around $d s x$ by B.S. Baker, G. Hoff, T.C. Kaufman and T. Hazelrigg (in prep.). The extents of deficiencies are indicated by thin lines. The shaded box at the end of $D f(3 R) A n t p^{N s+R 17}$ indicates the cytological uncertainty as to the location of its breakpoint. The locations of the breakpoints of inversions and translocations in the $d s x$ region are indicated by arrows.

tional chromosomal walk was carried out by isolating overlapping $\lambda$ clones containing Drosophila genomic inserts. This walk encompassed $73 \mathrm{~kb}$ of DNA (Fig. 3). To orient this walk relative to the chromosome and to locate the breakpoint of $D f(3 R) d s x^{M+R 2}$, individual EcoRI or $B a m H I$ restriction fragments from across the entire walk were labeled and used to probe Southern blots of restriction digests of genomic DNAs from two wild-type control stocks (Oregon $\mathrm{R}$ and Canton S) and a stock carrying the $D f(3 R) d s X^{M+R 2}$ chromosome. To help orient the walk (Fig. 2) we also analyzed genomic DNAs from two stocks carrying chromosomal rearrangements reported to be broken just proximal to the tubulin gene $\left[D f(3 R) S c x^{w+R 4}\right.$ (Hazelrigg and Kaufman 1983), and $T(2 ; 3) \mathrm{Ta}^{l}$ (Lewis et al. 1980)] and another rearrangement broken just distal to the $\alpha$-tubulin gene $\left[D f(3 R) S c X^{w+R 2}\right.$ (Hazelrigg and Kaufman 1983)]. At $+25 \mathrm{~kb}$ of this walk, the $D f(3 R) d s x^{M+R 2}$ chromosome contains a single novel $7.2-\mathrm{kb}$ EcoRI restriction fragment in place of a $10-\mathrm{kb}$ EcoRI fragment in wild type (Figs. 3 and 5a). This pattern is consistent with that expected for a deletion that fused DNA from another location in the genome to this portion of $84 \mathrm{C} 1-2$. Analogous results localized the breakpoints of $T(2 ; 3) T a^{I}$ and $D f(3 R) S c X^{w+R 2}$ to +34 and +41 $\mathrm{kb}$ of the walk, respectively (Fig. 3). These results place all three breakpoints distal to the $\alpha$-tubulin gene. The discrepancy with our starting information that $T(2 ; 3) T a^{l}$ was broken proximal to the $\alpha$-tubulin gene and the two deficiencies distal to it was resolved by cytology and genetic complementation tests. These showed that
$T(2 ; 3) \mathrm{Ta}^{l}$ is, in fact, broken distal to the $\alpha$-tubulin gene and also distal to the $84 \mathrm{Cl}-2$ breakpoint of $D f(3 R) d s x^{M+R 2}$ (data not shown) in agreement with the molecular localization of these breakpoints.

The screening of Southern blots of genomic DNAs with probes from across the $73 \mathrm{~kb}$ of this walk showed that except for the region from approximately -6 to +9 $\mathrm{kb}$ that contains the $\alpha$-tubulin gene, this DNA is unique. Thus, either the gene duplications that generated the $\alpha$ tubulin gene family (Kalfayan and Wensink 1981; Mischke and Pardue 1982) were relatively small or the flanking sequences have diverged substantially.

To obtain $d s x$ DNA, we cloned the 7.2-kb EcoRI fusion fragment generated by $D f(3 R) d s x^{M+R 2}$. A library of $E c o$ RI fragments from a stock heterozygous for this deletion was constructed in the $\lambda$-vector Charon 13 and screened with a probe from the region of the breakpoint in the walk. A phage carrying the $7.2-\mathrm{kb} E c o$ RI putative fusion fragment was isolated. Restriction mapping and Southern blot hybridizations showed that this fragment consists of $\sim 4.5 \mathrm{~kb}$ from the $84 \mathrm{Cl}-2$ region joined to $\sim 2.7 \mathrm{~kb}$ from elsewhere. The latter sequences were used to isolate phage 8 and 9(Fig. 4), presumably from the $d s x$ region. That these phage contained DNA from 84E1-2, the location of $d s x$ (B.S. Baker, G. Hoff, T.C. Kaufman, and T. Hazelrigg, in prep.) was confirmed by in situ hybridization to salivary gland polytene chromosomes.

\section{Cloning dsx and localization of flanking breakpoints}

Phage 8 and 9 DNAs were used to initiate a bidirectional walk through the $d s x$ locus. This walk encompassed 107 $\mathrm{kb}$ of DNA (Fig. 4).

Chromosomal rearrangements broken in or adjacent to the $d s x$ locus (Fig. 2) were used to determine the limits of the $d s x$ locus within this walk. To locate the breakpoints of these rearrangements, restriction digests of genomic DNAs from stocks heterozygous for these rearrangements and appropriate control stocks isee Methods) were probed with labeled restriction fragments from across the walk.

The proximal boundary on the $d s x$ locus was provided by the breakpoint of $D f(3 R) A n t p^{N s+R 17}$; this deficiency deletes all salivary gland chromosome bands and all known genes immediately proximal to $d s x$ but does not affect $d s x$ function. The distal boundary on $d s x$ was provided by $T(2 ; 3) E s$, a translocation whose $3 \mathrm{R}$ breakpoint is in a lethal complementation group in a very lightly staining salivary gland chromosome region immediately to the right of $d s x$. One lethal complementation group maps between $d s x$ and T(2;3)Es (B.S. Baker, G. Hoff, T.C. Kaufman, and T. Hazelrigg, in prep.). The patterns of hybridization observed on genomic Southern blots of $D f(3 R) A n t p^{N s+R 17}$ heterozygotes and $T(2 ; 3)$ Es heterozyotes are consistent with the expectations for a deficiency and a translocation whose breakpoints are at positions $-31 \mathrm{~kb}$ and $+42 \mathrm{~kb}$, respectively (Figs. 4 and $5 \mathrm{~b}$ ).

We confirmed the locations of the breakpoints of these rearrangements by cloning and characterizing the putative breakpoint fragments in both cases. The prox- 


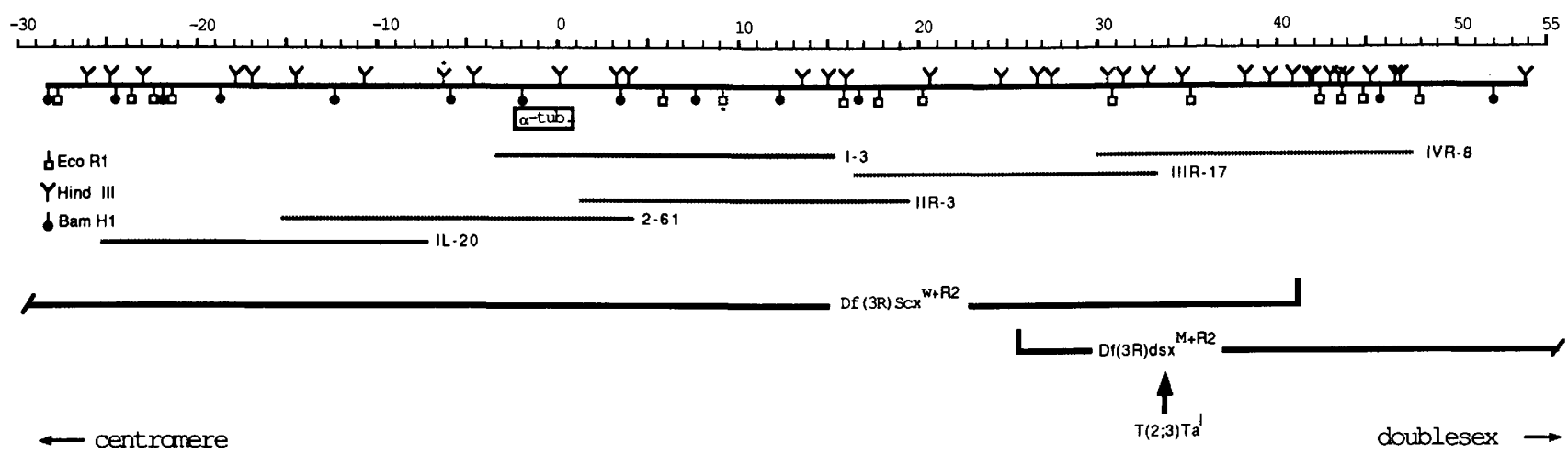

Figure 3. Restriction map of the 84B4-6 to $\mathrm{C} 1$ region. A restriction map of the region cloned in the walk to the site of the proximal breakpoint of $D f(3 R) d s x^{M+R 2}$. Position ' $\mathrm{O}$ ' is the site of the HindIII site in the $\alpha$-tubulin gene. Shaded horizontal lines indicate the extent of representative $\lambda$ clones of Drosophila genomic sequences recovered in the walk through this region. The starting clone (2-61) for the walk was provided by D. Mischke and M.L. Pardue (1982). The locations of the breakpoints of chromosomal rearrangements are marked with arrows. For deficiencies, lines indicate material that is deleted. The Canton $\mathrm{S}$ and Oregon $\mathrm{R}$ wild-type stocks examined were polymorphic for an $\sim 0.3$-kb insert in the $2.2-\mathrm{kb}$ EcoRI fragment located at +18 to $+20 \mathrm{~kb}$ whereas just the Canton $\mathrm{S}$ stock was polymorphic for a deletion of $\sim 0.2 \mathrm{~kb}$ in the region -4.5 to $-10.5 \mathrm{~kb}$. Restriction sites marked with an asterisk ( $\left.{ }^{\star}\right)$ were polymorphic in the library screened.

imal end of $D f(3 R) A n t p^{N s+R 17}$ maps cytologically within the region that has been cloned at the Antp complex (Scott et al. 1983). We showed that a 2.6-kb EcoRI-Sall clone of the putative fusion fragment from this deficiency was homologous to clones from the Antp region and that the breakpoint mapped between +1 and $+2 \mathrm{~kb}$ in the walk of Scott et al. (1983). Similarly, the cytological position of the second chromosome breakpoint of $T(2 ; 3)$ Es showed that it is very near, if not in, the engrailed (en) locus. Additionally, the genetic properties of this rearrangement suggest it affects the functioning of the en locus (B.S. Baker, G. Hoff, T.C. Kaufman, and T. Hazelrigg, in prep.). Thus, this breakpoint was also expected to be in a region that had been cloned (Kuner et al. 1985). Hybridization of a probe from the en region [the distal $7 \mathrm{~kb}$ of the $10-\mathrm{kb}$ EcoRI fragment from +28 to +38 in the walk of Kuner et al. (1985)] to a blot of restriction enzyme-digested clones containing the putative rearrangement fragment from this translocation confirmed that they contained sequences from the en region. The breakpoint mapped to between +32 and +33 in the walk of Kuner et al. (1985). Together, these results confirm that the breakpoints flanking the $d s x$ locus have been cloned, and therefore the entire $d s x$ locus must lie within the $\sim 73 \mathrm{~kb}$ region between -31 and +42 in our walk.

\section{Analysis of DNA in dsx mutants}

To localize $d s x$ more precisely within this $73-\mathrm{kb}$ segment of DNA, we determined the positions within this walk of the breakpoints of six inversions, five translocations, and two deficiencies, which had been shown genetically to break within the $d s x$ locus (Figs. 2 and 4). We inferred that these inversions and translocations were broken within $d s x$ from the fact that they are phenotypically null $d s x$ mutations that were generated by
$\mathrm{X}$-ray-induced inactivations of the dominant $d s x$ mutations $d s x^{D}$ or $d s x^{\text {Mas }}$, both of which genetically appear to express the $d s x$ male function constitutively (Duncan and Kaufman 1975; B.S. Baker, G. Hoff, T.C. Kaufman, and T. Hazelrigg, in prep.). That the two deficiencies $D f(3 R) d s X^{M+R 2}$ and $D f(3 R) d s X^{D+R 5}$ both probably had one of their ends in or near the $d s x$ locus was suggested by (1) cytological analysis, which showed that they each ended within salivary band $84 \mathrm{E} 1-2$, the position of $d s x$ (Fig. 2); (2) genetic studies, which showed that they failed to complement $d s x$ mutations and a number of lethal complementation groups to one side of $d s x$ (proximally, in the case of $D f(3 R) d s x^{M+R 2}$, and distally, in the case of $\left.D f(3 R) d s x^{D+R 5}\right)$ but did not delete any of the known genes on the other side of $d s x$; and (3) that $D f(3 R) d s x^{M+R 2} / D f(3 R) d s x^{D+R 5}$ individuals are viable and $d s x$ in phenotype.

To locate the breakpoints of the $d s x$ rearrangements, Southern blots comparing DNAs from flies heterozygous for these rearrangements and a balancer chromosome with those of appropriate control DNAs (see Methods) were probed with nick-translated DNA from cloned EcoRI restriction fragments from across the region. Novel size patterns of restriction fragments consistent with the expectations for the various kinds of rearrangements were detected at the positions indicated in Figure 4. The breakpoint of the one translocation $\left[T(2 ; 3) d s X^{M+R 1}\right]$ that was not detected using Southern blots was localized by in situ hybridization. The breakpoints in the inversions and translocations broken in $d s x$ map within an approximately $27-\mathrm{kb}$ region from the $8 \mathrm{p} 5$ fragment $(-5 \mathrm{~kb})$ to the $924 \mathrm{p} 58$ fragment $(+22 \mathrm{~kb})$. The ends of the two deletions that were thought to be within $d s x$ are also within this region (Fig. 4). These two deletions of $d s x$ are nonoverlapping and have their closest ends about $12 \mathrm{~kb}$ apart. The localization of these chromosomal rearrangements within the cloned region 

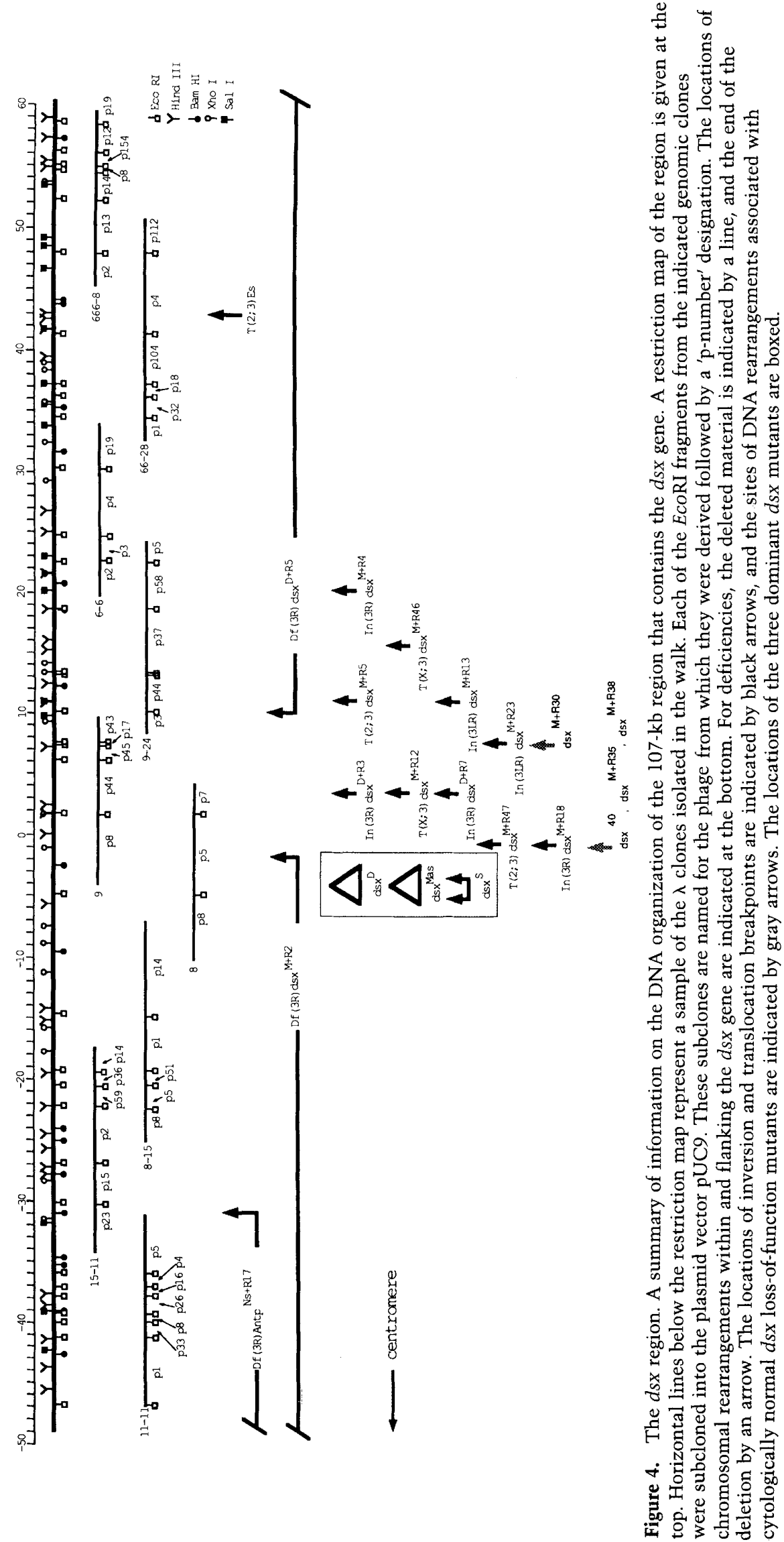
Figure 5. Autoradiograms of Southern blots of restriction digests of DNA from $d s x$ mutants. $(A)$ Novel EcoRI restriction fragment generated by $D f(3 R) d s X^{M+R 2}$. Lanes are $E c O R I$ digest of control (rucuca/TM2) (1) and Df(3R)dsX ${ }^{M+R 2} / T M 2$ (2) DNAs. Probe is the $10-\mathrm{kb}$ EcoRI fragment from - 20 to -30 in the walk at the $\alpha$-tubulin gene (Fig. 3 ). $(B)$ New restriction fragments generated by $T(2 ; 3)$ Es. Lanes are XhoI digests of control (Canton S) (1) and $T(2 ; 3)$ Es (2) DNAs. The probe is EcoRI fragments from +32 to +45 in the $d s x$ walk. (C) Novel HindIII fragment generated by the $0.6-\mathrm{kb}$ deletion associated with the dominant $d s x$ mutant $d s x^{s}$. Lanes are HindIII digests of the parent chromosome from which $d s x^{s}$ was derived (1) and $d s x^{s}(2)$. Probe is the 8 p5 EcoRI restriction fragment. (D) New band created by the middle repeat insertion associated with $d s X^{M a s}$. Lanes are BamHI digests of TM1/TM2 control (1) and $d s x^{\text {Mas }} /$ TM2 (2) probed with the $8 \mathrm{p} 5$ EcoRI restriction fragment. (E) Restriction digests of male and female DNAs. (Lanes 1 and 2) XhoI digests of male and female DNAs, respectively (lanes 3 and 4) SstI digests of male and female DNAs probed with the $8 \mathrm{p} 5$ EcoRI restriction fragment.

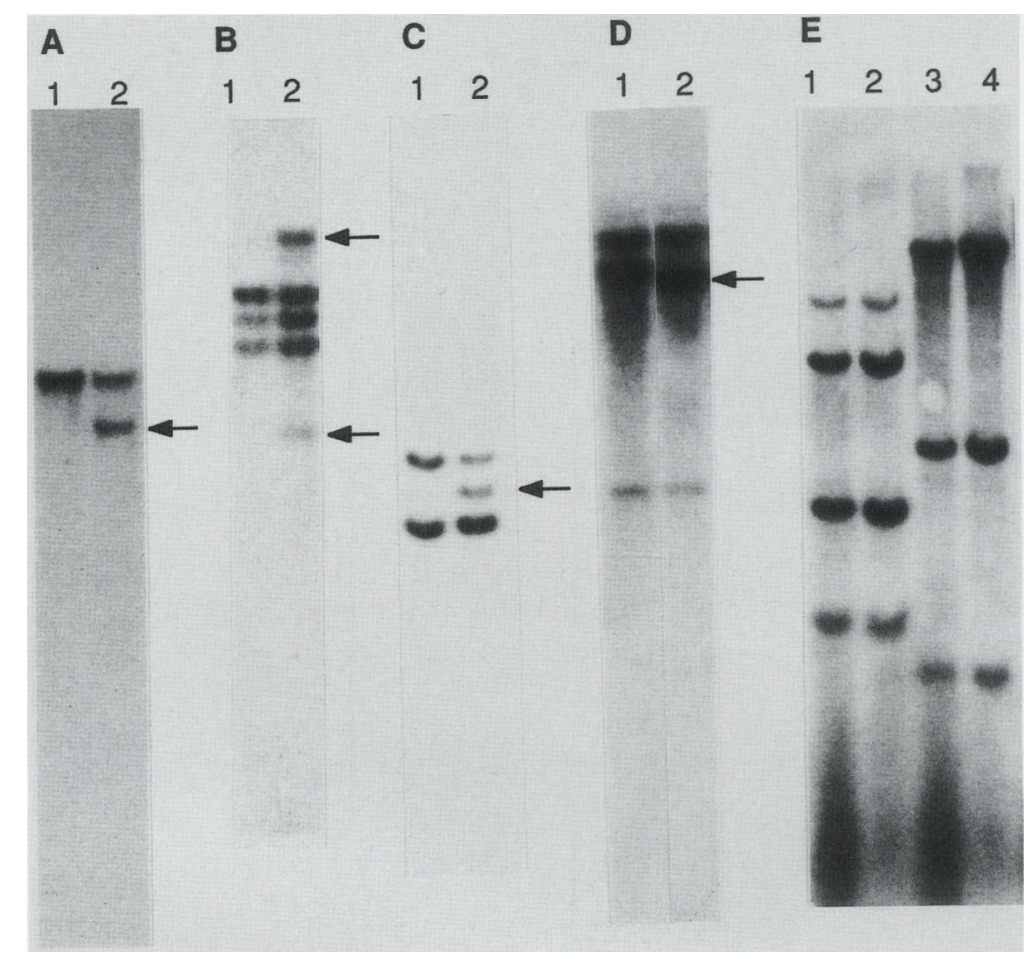

shows that sequences essential for the functioning of the $d s x$ gene extend across a region of at least $27 \mathrm{~kb}$, from approximately -5 to $+22 \mathrm{~kb}$ (Fig. 4).

Southern blots of restriction digests of DNAs from a number of cytologically normal $d s x$ mutants were also probed to see whether they contained molecularly detectable lesions in this region. Genetically, these 'point' mutations fall into two classes. The first class, which includes nearly all of the mutations, consists of simple recessive loss-of-function mutations. In the 18 [12 ethylmethanesulfonate (EMS)-induced, 1 spontaneous and 5 $\mathrm{X}$-ray-induced] mutations of this class that we examined, abnormalities in the restriction patterns in three of the X-ray-induced mutations $\left(d s X^{M+R 30}, d s X^{M+R 35}\right.$ and $\left.d s X^{M+R 38}\right)$ and one of the EMS-induced mutations $\left(d s x^{40}\right.$ were detected. All of the putative mutational lesions in these point mutants are within the region where the breakpoints of the cytologically detectable chromosomal aberrations in $d s x$ are found (Fig. 4).

The second class of $d s x$ point mutations that we examined are three dominant alleles that behave genetically as if they cause constitutive expression of the $d s x$ male function and are null for the $d s x$ female function. Thus, these mutations appear to be in sequences at $d s \mathrm{x}$ that are important for controlling the manner in which it is expressed. Two of these dominant mutants $\left(d s x^{D}\right.$ and $d s x^{M a s} \mid$ are of spontaneous origin, and no parent chromosomes are extant. The third dominant mutant, $d s x^{s}$, was induced by X-rays in an inbred background for which the parental chromosome is available (K. BrandtRosquist, pers. comm.). Probing Southern blots of restriction digests of genomic DNA from strains heterozygous for these dominant mutations revealed novel restriction patterns homologous to the $8 \mathrm{p} 5$ fragment (position -5 to $+1 \mathrm{~kb}$ ) in all three strains. These data suggest that $d s x^{M a s}$ and $d s x^{D}$ each have an insertion of DNA in this region, whereas the $d s x^{s}$ chromosome appeared to have a deletion of approximately $0.6 \mathrm{~kb}$ (Fig. $5 \mathrm{C}$. The fact that all three dominant $d s x$ mutants are associated with rearrangements in the same short DNA segment suggests that this region contains sequences that are important for the regulation of $d s x$ expression.

To characterize the defects in these mutants more fully, $\lambda$ libraries of genomic DNA from stocks of each of these mutants were made, and the phage bearing the altered fragments homologous to $8 \mathrm{p} 5$ were isolated. In all three cases, the putative mutational lesion mapped to within the $2-\mathrm{kb}$ BamHI-EcoRI $(-2.5$ to -4.5$)$ segment at the centromere proximal end of the $8 \mathrm{p} 5$ fragment (Fig. 4). The $d s x^{\text {Mas }}$ chromosome has an insert of $\sim 3.9 \mathrm{~kb}$, about $0.7 \mathrm{~kb}$ to the left of the BamHI site at position -2.5 (Fig. 5D). Genomic Southern blots probed with the insert DNA indicate that sequences homologous to this insert are present about 50-100 times in the Drosophila genome, and thus it may represent a mobile middle repeat element. The $d s x^{D}$ chromosome also contains a middle repeat element, in this case, of approximately 7.7 $\mathrm{kb}$, inserted to the left of the BamHI site at -2.5 and within $1.85 \mathrm{~kb}$ of it. This middle repeat element does not appear to be clonable in an intact form in $\lambda$ EMBL3 vector, because of 27 clones containing this region isolated from a library of DNA from a stock heterozygous for $d s x^{D}$ and a wild-type chromosome, 23 contained sequences from the wild-type third chromosome and all of the 4 that contained sequences from the $d s x^{D}$ chromosome had only a partial element. However, all pieces of the element appear to be clonable because phage clones that contain either the left or the right part of the ele- 
ment and overlap in the middle were obtained. The insert in $d s x^{D}$ is not homologous to either the FB element (Potter et al. 1980) or I element (Bucheton et al. 1984), two Drosophila middle repeat elements with properties similar to this repeat. Restriction analysis of the clones derived from the $d s x^{s}$ chromosome in this region confirmed that it contained a $0.6-\mathrm{kb}$ deletion within the BamHI-HindIII fragment located at -2.5 to -5.5 .

\section{dsx DNA organization in wild-type adults}

The $d s x$ locus shows a number of similarities to the MAT locus of yeast (Nasmyth 1982) in its biological role and its genetic properties. Because the MAT locus contains different DNAs in the two yeast mating types, we asked whether the DNA organization of the $d s x$ locus was the same in differentiated male and female flies. Genomic DNAs from wild-type adult males and females were digested with individual members of a battery of 13 restriction enzymes with 6-base recognition sites, electrophoresed, and transferred to nitrocellulose. These blots were probed with each of the individual EcoRI fragments from -25 to $+50 \mathrm{~kb}$ in the region containing the $d s x$ locus (Fig. 5E). In no case were there differences seen between the restriction digests of male and female DNAs. These results suggest that genomic rearrangements probably do not play a role in the regulation of $d s x$ expression.

These hybridizations also failed to detect any bands not predicted by the restriction map of the $d s x$ locus, suggesting that the $d s x$ locus is not duplicated elsewhere in the genome. To examine more closely whether there were any regions of internal homology at $d s x$, Southern blots of digests of phage containing DNA from -47 to $+60 \mathrm{~kb}$ in the $d s x$ region were hybridized with nicktranslated probes corresponding to the individual EcoRI restriction fragments that spanned the region from -35 to $+48 \mathrm{~kb}$. Again, no unexpected homologies were detected under normal hybridization conditions. These results suggest that there are no sequences related to $d s x$ in the genome that can be detected under our normal hybridization conditions. Nor are there any large duplications within the $d s x$ region itself.

\section{RNA analysis of the dsx region}

The experiments described above establish that the entire $d s x$ gene must lie within the $73-\mathrm{kb}$ interval between the breakpoints of $D f(3 R) A n t p^{N s+R 17}$ and $T(2 ; 3) E s$ and that the $d s x$ locus must span the $\sim 27-\mathrm{kb}$ portion of this interval (from $-5 \mathrm{~kb}$ to $+22 \mathrm{~kb}$ ) in which $d s x$ null breakpoints are found. To identify the transcripts of the $d s x$ locus, nick-translated probes made from the individual EcoRI restriction fragments from across an $82-\mathrm{kb}$ region, including the breakpoints of $T(2 ; 3) E s$ and $D f(3 R) A n t p^{N s+R 17}$ were hybridized to Northern blots of poly $(\mathrm{A})^{+}$RNAs isolated from populations of mixed males and females at different stages of development. For regions where transcripts were detected in these experiments, Northern blots of poly(A) ${ }^{+}$RNAs prepared from separated males and females were probed to determine whether the transcripts were sex-specific. We first describe the results of these experiments for the regions between the flanking breakpoints and the breakpoints that inactivate $d s x$.

\section{Transcripts in the regions flanking dsx}

In the $28-\mathrm{kb}$ region $(+20$ to $+48 \mathrm{~kb})$ distal to the location of the $d s x$ breakpoints, there are two size classes of transcripts $(2.6$ and $2.3 \mathrm{~kb})$ detected. Both of these transcripts are found in all developmental stages and in equivalent amounts in males and females. The $2.3-\mathrm{kb}$ transcript is detected by probes corresponding to the EcoRI fragment $(6628 \mathrm{p} 4)$ in which $T(2 ; 3)$ Es is broken and, thus, probably corresponds to the lethal complementation group of which $T(2 ; 3) E s$ is an allele (B.S. Baker, G. Hoff, T.C. Kaufman, and T. Hazelrigg, in prep.). Genetic studies identified only one other gene, also a lethal complementation group, between $d s x$ and the lethal complementation group containing $T(2 ; 3) E s$ (B.S. Baker, G. Hoff, T.C. Kaufman, and T. Hazelrigg, in prep.); we infer that the $2.6-\mathrm{kb}$ transcript detected in this interval corresponds to this gene.

In the 29-kb interval proximal to the location of the $d s x$ breakpoints $(-5$ to -34$)$, there were eight size classes of transcripts detected. It is likely that these represent the differential processing products of five transcription units because several transcripts are detected by the same array of probes. Six of these transcripts are present throughout development and in equivalent amounts in males and females at the stages examined. In two cases $1 \mathrm{a} 4.3-\mathrm{kb}$ transcript detected by probes from -15 to $-22 \mathrm{~kb}$ and a $1.6-\mathrm{kb}$ transcript detected by probes from -20 to $-27 \mathrm{~kb}$ ), transcripts were detected only in atult females and embryos (and pupae of mixed males and females in the case of the 1.6-kb transcript) but not in adult males or other developmental stages. In the case of these two transcripts, the same set of probes also detected slightly smaller transcripts in both sexes throughout development. The pattern of appearance of these RNAs is thus consistent with the possibility that these are genes that are expressed both maternally and zygotically and that the transcripts produced in the female germ line differ slightly from those produced during development. Genetic studies (B.S. Baker, G. Hoff, T.C. Kaufman, and T. Hazelrigg, in prep.) have not identified any mutations, other than those at $d s x$, mapping into the region where these transcripts are found [between the breakpoints of $D f(3 R) d s x^{M+R 2}$ and $\left.D f(3 R) A n t p^{N s+R 17}\right]$. Thus, in principle, some or all of them could represent products of the $d s x$ locus. This seems unlikely to us because all of these transcripts are derived from portions of the genome that are $10 \mathrm{~kb}$ or more from the nearest breakpoint that inactivates the $d s x$ locus. This conclusion is reinforced by the findings (described below) with respect to the sexual and temporal pattern of transcripts produced by the region known to be at least part of the $d s x$ locus by breakpoint analysis. 


\section{Transcripts at dsx}

The $40-\mathrm{kb}$ region $(-10$ to +30$)$ containing the $d s x$ null breakpoints is transcribed to produce a sexually and temporally modulated array of transcripts. A summary of the pattern of transcripts that are seen when Northern blots of male and female poly $(\mathrm{A})^{+}$RNAs are hybridized with probes corresponding to the EcoRI fragments from across this region is presented in the right part of Figure 6, and the various EcoRI fragments that are homologous to each of these transcripts are presented in the left part of Figure 6. Examples of Northern blots are presented in Figure 7 . The major $d s x$ transcripts produced during development in the two sexes are as follows.

Throughout the larval period, two transcripts of 2.8 and $1.65 \mathrm{~kb}$ are present in both males and females (Figs. 6 and 7a). These sex-nonspecific transcripts appear in the first instar and are present at relatively constant levels throughout the larval period and then decrease drastically in amount (and may disappear) at the end of the larval period. We believe that these transcripts are the result of differential processing of a primary transcript because they are homologous to the same probes at their $3^{\prime}$ and $5^{\prime}$ ends but differ in their pattern of homology to internal fragments.

Both male-specific and female-specific transcripts appear at the end of the larval period (Figs. 6 and $7 \mathrm{~b}$ ). The major sex-specific transcripts seen in pupae are a $3.8-\mathrm{kb}$ male-specific transcript and a $3.2-\mathrm{kb}$ female-specific transcript. These sex-specific transcripts are homologous to noncontiguous genomic fragments spanning a region of about $40 \mathrm{~kb}$ and, thus, appear to represent the products of differential RNA processing. This has been confirmed by the isolation and sequencing of cDNAs that correspond to these male-specific and female-specific pupal transcripts and determining their directions of transcription (Baker et al. 1987; K.C. Burtis and B.S. Baker, in prep.). These data show that these transcripts share common $5^{\prime}$ exons but have different exons at their $3^{\prime}$ ends. In addition to these transcripts, bands of about $3,1.7$, and $1 \mathrm{~kb}$ are occasionally observed on some Northern blots of male pupal RNA (Fig. 7); whether these represent additional transcripts or breakdown or processing products is currently unclear. A band of greater than $10 \mathrm{~kb}$, which we suspect may be a processing intermediate, is also seen frequently.

Our results, using nick-translated probes, suggest that the sex-specific 3.2- and 3.8-kb 'pupal' transcripts are absent in adults. However, more sensitive experiments using single-stranded, transcript-specific probes have shown that both the pupal male- and female-specific transcripts are also present in the adult at substantially reduced levels (K.C. Burtis and B.S. Baker, in prep.). In addition, a small $0.7-\mathrm{kb}$ male-specific transcript appears in the adult (Figs. 6 and 7).

\section{Discussion}

We have cloned the $d s x$ gene by means of two sequential chromosomal walks of 73 and $107 \mathrm{~kb}$. These walks were bridged by jumping via a deficiency that brought sequences from these two regions into close proximity. Within the walk that actually encompassed the $d s x$ locus, the locations of the closest available breakpoints flanking $d s x$ indicate that all sequences necessary for the expression of $d s x$ reside within a region of $73 \mathrm{~kb}$. Within this region, the $d s x$ locus was further localized by determining the positions of chromosomal rearrangements that were broken within the $d s x$ gene. The chromosomal rearrangements broken within the $d s x$ locus were all derived as X-ray-induced inactivations of dominant $d s x$ mutants. Because these dominant $d s x$ mutants
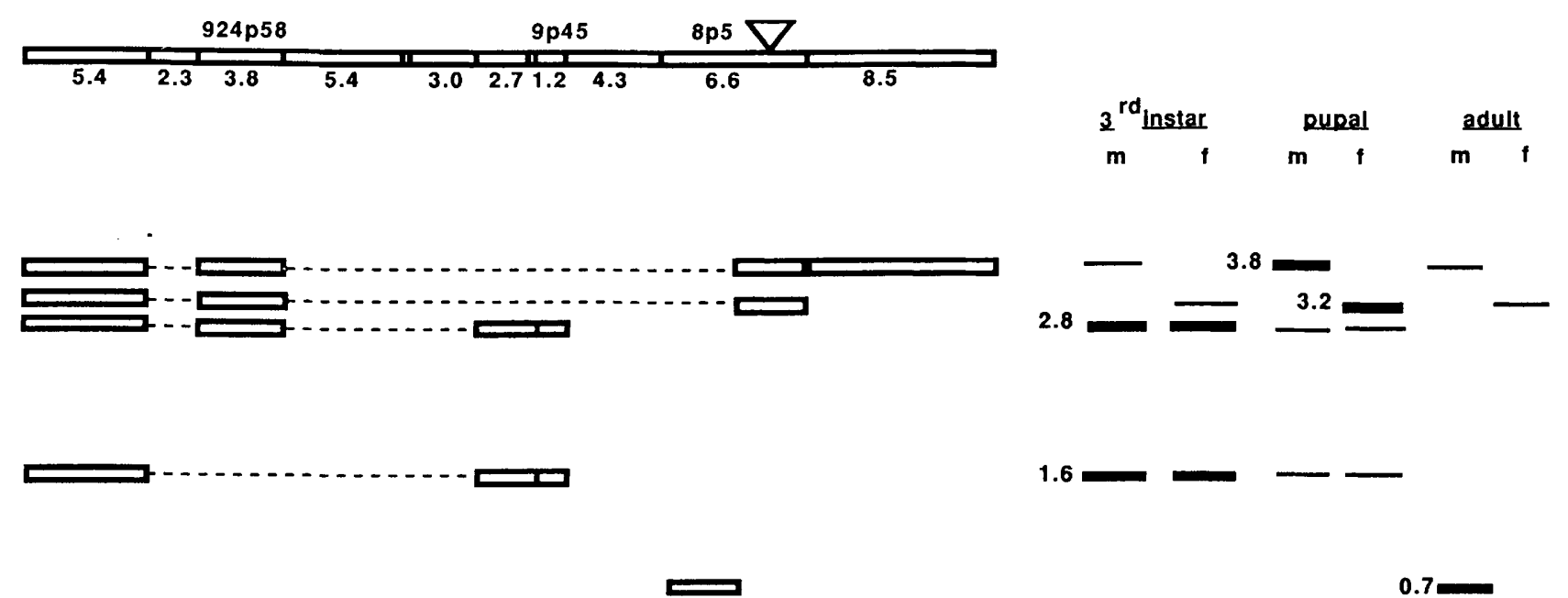

0.7

Figure 6. Schematic representation of the pattern of transcripts produced by the $d s x$ locus and the portions of the genome from which they are derived. On the right are the $d s x$ transcripts detected at different stages in males $(\mathrm{m})$ and females (f). The thickness of a line for a given transcript indicates its relative abundance at different stages. On the top left is the EcoRI map of the $d s x$ gene. Below this, the open boxes on a line indicate the EcoRI fragments that are homologous to each transcript in the right half of the figure. The portions of the $8 \mathrm{p} 5$ EcoRI fragment from which the pupal and adult transcripts are derived were determined using BamHI-EcoRI subclones of this fragment. 
behave as though they are constitutively expressing the $d s x$ male function and are null for the $d s x$ female function, the rearrangements we have positioned on our walk identify sequences that are necessary for the $d s x$ male function. These breakpoints, which are located across a region of $\sim 27 \mathrm{~kb}$, thus define a minimal extent of the $d s x$ locus. The $d s x$ DNA is unique in the genome and has the same restriction map in males and females; thus, gross DNA rearrangements such as those seen in the MAT locus of yeast do not appear to be involved in the regulation of $d s x$.

Mutagenesis and deficiency mapping of both lethal and visible mutations in a region of about 30 salivary gland chromosome bands that included the $d s x$ locus showed that it was closely flanked by lethal complementation groups of apparently unrelated functions and thus suggested that $d s x$ is not part of a sex determination gene complex (B.S. Baker, G. Hoff, T.C. Kaufman, and T. Hazelrigg, in prep.). The patterns of transcription in the regions immediately flanking the $d s x$ locus are consistent with this genetic conclusion. Transcripts in these flanking regions do not show sex-specific patterns of appearance that would be indicative of a possible role in sex determination. In the region distal to $d s x$, there are two transcription units that are expressed in both sexes throughout development. Two lethal complementation groups are known to reside in this region, and each presumably encodes one of the two transcripts. The region proximal to the breakpoints of the $d s x$ null rearrangements produces eight different size classes of transcripts, probably representing five transcription units. Although two of these transcripts appear to be present primarily in adult females and embryos, this is not the pattern of expression expected from genetic studies for the $d s x$ locus (Baker and Ridge 1980). The remainder of these transcription units are expressed at relatively constant levels throughout development, suggesting that they may represent housekeeping functions.

Northern blot analysis of the $40-\mathrm{kb}$ region that encompasses the $d s x$ breakpoints reveals a pattern of sexually and temporally regulated transcripts that, at least in part, fits nicely with the previous genetic analysis of $d s x$ function, which showed that the $d s x$ gene has active, but opposite, regulatory functions in the two sexes (Baker and Ridge 1980). There are two transcripts that are found in both sexes throughout the larval period. At about the end of the larval period, these sex-nonspecific transcripts disappear and male-specific and female-specific transcripts appear. These pupal sex-specific transcripts peak in amount during the pupal period but are also found at much reduced levels in adults. In addition, a new small male-specific transcript appears in the adult.

The fact that distinct male- and female-specific $d s x$ transcripts are produced beginning in the late larval period is consistent with both the facts that $(1) d s x$ has different active roles in controlling sexual differentiation in the two sexes and (2) transcription of the $d s x$ gene is needed in the pupal period for normal sexual differentiation (Baker and Ridge 1980). Given the correla- tion of the sexual and temporal patterns of appearance of these transcripts with the pattern of activity of $d s x$ that is revealed by genetic studies, it is likely that these transcripts represent the functional products of the $d s x$ gene that are seen by the aforementioned genetic analysis. It should be noted, however, that in one sexually dimorphic tissue, the genital disk, the functioning of this regulatory hierarchy is apparent substantially earlier (in the second larval instar; Wieschaus and Nöthiger 1982) than it is in the other tissues. We suspect that the sensitivity of our Northern blots was such that if the sex-specific pupal transcripts were being expressed in only a few cells or at a low level at earlier stages, we would have failed to detect them.

The large number of transcripts at the $d s x$ locus was unexpected from its genetic analysis. The temporal patterns of appearance of the larval sex-nonspecific and the adult male-specific transcripts are inversely related to those of the sex-specific pupal transcripts, suggesting that these transcripts are not from overlapping genes unrelated to $d s x$. The situtation has similarities to the two other Drosophila sex determination regulatory genes, Sxl (Maine et al. 1985a,b) and tra (Butler et al. 1986; McKeown et al. 1986, 1987), that have been studied at the molecular level. Genetic analysis has shown that both of these genes carry out female-specific regulatory functions; yet tra produces both a sex-nonspecific and a female-specific transcript, whereas in the case of $S \times 1$, there are several male-specific and femalespecific transcripts.

The analysis of mutations at the Sxl, tra, and $d s x$ loci has substantially delimited the possible roles of these unexpected transcripts. There are mutations at both $S x I$ and tra that are small deletions, which remove the regions encoding the male-specific or sex-nonspecific. transcripts (Belote et al. 1985; Maine et al. 1985a,b; McKeown et al. 1986, 1987). These deletions are homozygous viable in males in whom they have no phenotypic effects. In the case of the $d s x$ locus, there are inversions and translocations that interrupt the region that is homologous to both the larval- and the pupal-specific transcripts. These mutations have phenotypic effects that are indistinguishable from those of phenotypically null point mutants or chromosomal rearrangements that are broken in the portion of $d s x$ that is homologous to only the sex-specific pupal transcripts. Thus, in the case of all three loci, these sex-nonspecific transcripts may be without biological functions and be produced solely as a consequence of the properties of the transcriptional machinery of the cell. In the case of tra, this conclusion is reinforced strongly by the analysis of the structure of the tra transcripts, which shows that the sex-nonspecific transcript does not have any substantial open reading frame, whereas the female-specific transcript has a long open reading frame (Boggs et al. 1987).

The temporal and sex-specific changes seen in the pattern of transcription of the $d s x$ locus suggest that a major aspect of its regulation occurs at the level of transcription and/or transcript processing. Moreover, the pattern of $d s x$ transcription changes in a similar fashion 


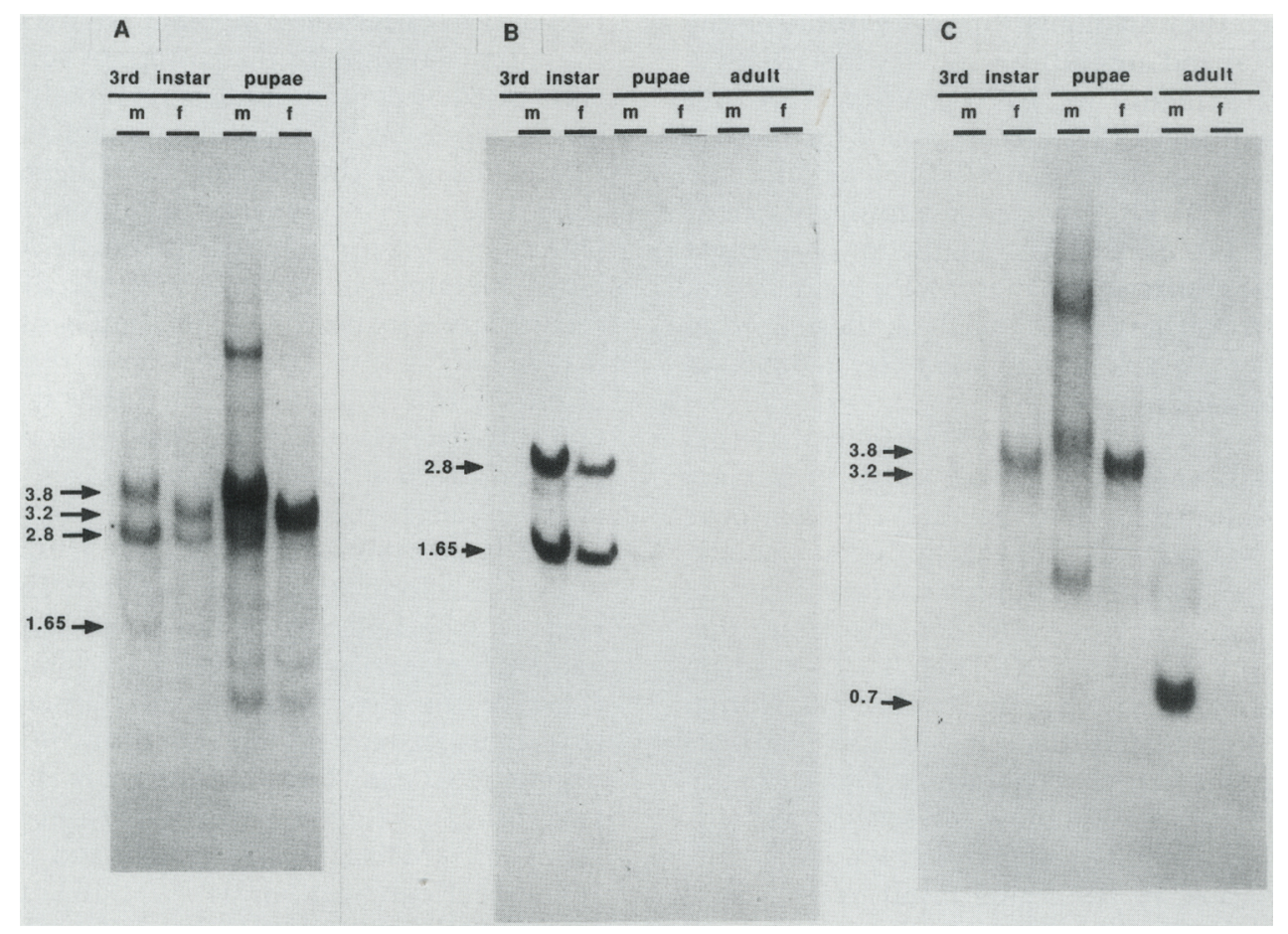

Figure 7. Northern blots of male $(\mathrm{m})$ and female $(\mathrm{f})$ poly $(\mathrm{A})+$ RNAs from the indicated developmental stages probed with nick-translated genomic EcoRI fragments from the $d s x$ gene. Each lane contained $20 \mu \mathrm{g}$ of poly $(\mathrm{A})^{+} \mathrm{RNA}$ from flies of the indicated sex and developmental stage. Probes were (as in Fig. 5): (Panel A) 924p58 $(+18.7$ to +23.5$)$; (panel $B) 9 \mathrm{p} 45(+6$ to +7.2$) ;(\mathrm{panel} C) 8 \mathrm{p} 5(+1.7$ to $-4.9)$.

in the two sexes at the end of the larval period: The amount of the sex-nonspecific transcripts decreases drastically and the sex-specific transcripts appear. When the latter observations are considered in terms of what is known about the control of $d s x$ expression in the two sexes, it is clear that there is an additional level of control on the expression of $d s x$ beyond those deduced from genetic studies. Thus, both genetic and molecular studies suggest that the expression $d s x^{+}$requires the sequential functioning of the $S \times l$, tra, and tra-2 loci in females (Fig. 1; Baker and Ridge 1980; R.N. Nagoshi et al. 1988). However, the sex-specific transcripts of the $S \times 1$ (Maine et al. 1985a,b) and tra (McKeown et al. 1987) loci are present substantially before the appearance of the female-specific $d s x$ transcript. Similarly, in males, there are no sex determination regulatory functions known that act between the determination of the X chromosome: autosome ratio in the embryo and the functioning of $d s x$. Taken together, this suggests that there is an additional regulatory signal that acts at the end of the larval period in both sexes and is necessary for the change in the pattern of $d s x$ expression at that time.

The need for such a signal may derive from the fact that Drosophila can, depending on the temperature at which it develops, take anywhere from about 4.5 days to 2 weeks to reach the end of the larval period. Because there is no apparent reason to impose the adult pattern of expression on the genes utilized in terminal adult differentiation until their adult patterns of expression are needed beginning in the late larval/early pupal period, it would make sense that there is a mechanism that tells the organism when it is the proper time to so express such terminal differentiation genes. These considerations suggest that the changes in the pattern of $d s x$ transcription at the end of the larval period may reflect the action of such a regulatory mechanism.

The suggestion, based on temporal considerations, that the signal initiating the production of the sex-specific $d s x$ transcripts at the end of the larval period is the same in the two sexes is strongly reinforced by the isolation and sequencing of cDNAs that correspond to these transcripts (Baker et al. 1987; K.C. Burtis and B.S. Baker, in prep.). These transcripts have three exons at their $5^{\prime}$ ends in common but differ in the exons at their $3^{\prime}$ ends. These data suggest that at the end of the larval period, a common regulatory event in the two sexes allows the production of a primary $d s x$ transcript that is then differentially processed in a sex-specific manner. The simplest model consistent with genetic considerations suggests that the wild-type tra and tra-2 products are responsible for this processing in females and, moreover, that the presence of the wild-type tra and tra-2 gene products in females is the sole difference between the sexes in the regulation of $d s x$ expression. Our reasoning is as follows. An active function of the $d s x$ locus is required in both males and females for normal sexual differentiation: Null $d s x$ mutants transform both chromosomally male and female individuals into intersexes. However, the absence of either the tra or tra-2 function in a chromosomally female individual does not trans- 
form that individual into an intersex (as would be expected if no functional $d s x$ product were being made in these individuals), but rather into a male. This implies that the $d s x$ male function is expressed in a female in the absence of the products of the tra loci (Baker and Ridge 1980) and, further, that females have everything necessary to process the primary $d s x$ transcript into the male product but normally fail to do so only because the sequential action of the wild-type products of the $S x l$, tra, and tra-2 loci lead to the alternative (female-specific) pattern of RNA process. Recently, this has been shown to be the case by the finding that in chromosomally female individuals homozygous for either an $S x l$, tra, or tra-2 mutation, the $d s x$ male transcript is produced and the $d s x$ female transcript is not produced (R.N. Nagoshi et al. 1988).

The analysis of the three dominant $d s x$ mutants that we have examined not only reinforces this view but also suggests the location of a cis-acting site that is necessary for the production of the $d s x$ female product. These three dominant $d s x$ mutants all have the same phenotype, and it suggests that they constitutively express the $d s x$ male function and are unable to express the $d s x$ female function. We have shown that $d s x^{M a s}$ and $d s x^{D}$ are each associated with an insertion of a middle repeat element in the $d s x$ locus, whereas the $d s x^{s}$ mutant is associated with a deletion of $\sim 0.6 \mathrm{~kb}$. Because the parent chromosome from which $d s x^{s}$ was derived is available and does not contain this deletion, $d s x^{S}$ is almost certainly due to this deletion. For the $d s x^{D}$ and $d s x^{\text {Mas }} \mathrm{mu}$ tations, parental chromosomes are not available. However, the inference that these two mutations are due to these middle repeat sequences is substantially strengthened by our finding that the molecular lesions associated with all three of the dominant $d s x$ mutants map to within a $2-\mathrm{kb}$ portion of the $40-\mathrm{kb} d s x$ transcription unit and could, in fact, encompass the same site. Further mapping of lesions associated within these three dominant $d s x$ mutants shows that they all reside within the $3^{\prime}$ female-specific $d s x$ exon (R.N. Nagoshi and B.S. Baker, unpubl.). The finding that these mutants are all associated with lesions in the same portion of the $d s x$ gene strongly suggests that this is the location of a site that is necessary for the expression of the $d s x$ female function. We suggest that when these sequences are disrupted, the products of the $t r a^{+}$and $t r a-2^{+}$loci are unable to direct the production of the $d s x$ female product and that the $d s x$ male product is produced instead as a consequence of the action of the housekeeping RNA processing machinery.

\section{Methods}

DNA and clone isolation and manipulation

The screening of recombinant DNA libraries, plasmid and bacteriophage DNA isolation, restriction endonuclease digestions, agarose gel electrophoresis, Southern blot transfers to nitrocellulose filters, DNA fragment isolation from gels, nick translations, hybridization to DNA on filters, ligations, and subcloning of DNA into plasmid vectors were carried out essen- tially as described in Maniatis et al. (1978). Drosophila genomic DNA was isolated as described in Bender et al. (1983). Southern blots were hybridized with nick-translated probes in $5 \times$ SSPE, $50 \%$ formamide, $2 \times$ Denhardt's solution, $0.2 \%$ SDS, and 50 $\mu \mathrm{g} / \mathrm{ml}$ salmon sperm DNA at $42^{\circ} \mathrm{C}$ and washed $4 \times$ for $1 \mathrm{hr}$ in $0 . \mathrm{I} \times \mathrm{SSPE}$ and $0.1 \%$ SDS at $50^{\circ} \mathrm{C}$ (Maniatis et al. 1978).

\section{Recombinant DNA libraries}

A library of wild-type (Canton S) D. melanogaster DNA inserted in the Charon 4 phage vector (Maniatis et al. 1982) was used for the chromosomal walks. A library of the deficiency $D f(3 R) d s X^{M+R 2}$, used to jump from salivary region $84 C 1-2$ to $d s x$ (84E1-2), was constructed by digesting adult fly DNA with EcoRI, ligating these fragments to purified arms of EcoRI-digested Charon 13 phage (Williams and Blattner 1979), and carrying out an in vitro packaging reaction. Libraries of the three dominant $d s x$ mutants $\left(d s x^{D}, d s x^{M a s}\right.$, and $\left.d s x^{s}\right)$ and the two rearrangements $\left[D f(3 R) A n t p^{N s+R 17}\right.$ and $\left.T(2 ; 3) E s\right]$, whose breakpoints flank the $d s x$ locus, were constructed by partially digesting adult fly DNA with $M b o I$, size fractionating the DNA on agarose gels, ligating the $12-$ to $20-\mathrm{kb}$ size range fragments into the BamHI site of EMBL3 phage (Murray 1983), and carrying out an in vitro packaging reaction.

\section{Localization of rearrangement breakpoints}

All of the rearrangements whose breakpoints we localized by probing Southern blots are either homozygous lethal or sterile and are kept in stock over multiply inverted homozygous lethal 'balancer' chromosomes. To ensure that novel DNA fragments potentially indicative of a rearrangement breakpoint were, in fact, derived from the rearrangement-bearing chromosome and not the balancer chromosome, digests of DNA from stocks carrying the balancer chromosome and either a wild-type homolog or a homolog carrying a complete deletion of the region of interest were probed as controls. When available (including all of the $d s x^{M a s}$ and $d s x^{D}$ revertants and the $d s x^{s}$ mutant chromosomes analyzed here|, DNA from the parental chromosomes from which mutants were derived was also analyzed as a control.

\section{Preparation and analysis of RNAs}

Large numbers of larvae, pupae, and adults of a specific sex were generated using the cinnamon mutation (Baker 1973). RNA was prepared essentially as described by Poole et al. (1985). Oligo(dT) cellulose chromatography was essentially as described by Maniatis et al. (1982).

RNA was separated on vertical $1 \%$ agarose-formaldehyde gels prepared in $50 \mathrm{~mm}$ HEPES and mM EDTA (pH 7.8). RNAs were blotted to nitrocellulose (Thomas 1980) and probed with nick-translated DNA fragments in $5 \times$ SSPE, $50 \%$ formamide, $2 \times$ Denhardt's solution, $0.2 \%$ SDS, and $50 \mu \mathrm{g} / \mathrm{ml}$ salmon sperm DNA at $45^{\circ} \mathrm{C}$ and washed $4 \times$ for $1 \mathrm{hr}$ in $0.1 \times$ SSPE and $0.1 \%$ SDS at $50^{\circ} \mathrm{C}$.

\section{Fly culture}

Flies were raised on a standard cornmeal, molasses, yeast, and agar media containing proprionic acid as a mold inhibitor and supplemented with live yeast. Descriptions of all mutants and rearrangements not specifically referenced in the text can be found in Lindsley and Grell (1968). 


\section{Acknowledgments}

This work was supported by a grant from the National Institutes of Health. M.F.W. was supported by a postdoctoral fellowship from the Damon Runyon-Walter Winchell Cancer Fund. We would like to express our gratitude to K. Brandt-Rosquist for giving us the $d s x^{s}$ mutant, to A. Garen and J. Belote for giving us $d s x$ point mutants, D. Mischke and M.-L. Pardue for the $\alpha$-tubulin clone, M. Scott for Antp region clones, and T. Kornberg for probing a Southern blot of clones of the $T(2 ; 3) E S$ breakpoint region DNA with a probe from the en region. In addition, we would like to express our special appreciation to $\mathrm{K}$. Burtis, R. Nagoshi, G. Joslyn, and B. Taylor, who contributed to mapping some of the rearrangement breakpoints and the accuracy of our maps. Finally, we would like to thank D. Andrew, K. Burtis, A. Carpenter, B. Chase, T. Goralski, M. Kuoda, and W. Mattox for their comments on this manuscript.

\section{References}

Baker, B.S. 1973. The maternal and zygotic control of development by cinnamon, a new mutant in Drosophila melanogaster. Dev. Biol. 33: 429-440.

Baker, B.S. and J.M. Belote. 1983. Sex determination and dosage compensation in Drosophila melanogaster. Annu. Rev. Genet. 17: 345-397.

Baker, B.S. and K. Ridge. 1980. Sex and the single cell: On the action of major loci affecting sex determination in Drosophila melanogaster. Genetics 94: 383-423.

Baker, B.S., R.N. Nagoshi, and K.C. Burtis. 1987. Molecular genetic aspects of sex determination in Drosophila. BioEssays 6: $66-70$.

Belote, J.M., M. McKeown, D.J. Andrew, T.N. Scott, M.F. Wolfner, and B.S. Baker. 1985. Control of sexual differentiation in Drosophila melanogaster. Cold Spring Harbor Symp. Quant. Biol. 50: 605-614.

Bender, W., P. Spierer, and D.S. Hogness. 1983. Chromosome walking and jumping to isolate DNA from the Ace and rosy loci and the bithorax complex in Drosophila melanogaster. J. Mol. Biol. 168: 17-33.

Boggs, R.T., P. Gregor, S. Idriss, J.M. Belote, and M. McKeown. 1987. Regulation of sexual differentiation in Drosophila melanogaster via alternative splicing of RNA from the transformer gene. Cell 50: 739-747.

Bridges, C.B. 1921. Triploid intersexes of Drosophila melanogaster. Science 54: 252-254.

Bucheton, A., R. Paro, H.M. Sang, A. Delisson, and D.J. Finnegan. 1984. Molecular biology of I-R hybrid dysgenesis in Drosophila melanogaster: Identification cloning and properties of the I factor. Cell 38: 153-163.

Butler, B., V. Pirotta, I. Irminger-Finger, R. Nöthiger. 1986. The sex-determining gene tra of Drosophila: Molecular cloning and transformation studies. EMBO J. 5: 3607-3613.

Cline, T.W. 1978. Two closely-linked mutations in Drosophila melanogaster that are lethal to opposite sexes and interact with daughterless. Genetics 90: 683-698.

- 1984. Autoregulatory functioning of a Drosophila gene product that establishes and maintains the sexually determined state. Genetics 107: 231-277.

- 1985. Primary events in the determination of sex in Drosophila melanogaster. In Origin and evolution of sex. (ed. H.O. Halvorson and A. Monroy), pp. 301-327. Alan R. Liss, New York.

1986. A female-specific lethal lesion in an X-linked positive regulator of the Drosophila sex determination gene, Sex-lethal. Genetics 113: 641-663.
Duncan, I. and T. Kaufman. 1975. Cytogenetic analysis of chromosome 3 in Drosophila melanogaster: Mapping of the proximal portions of the right arms. Genetics 80: 733-752.

Garcia-Bellido, A. 1977. Homeotic and ativic mutation in insects. Am. Zool. 17: 613-629.

Hazelrigg, T. and T.C. Kaufman. 1983. Revertants of dominant mutations associated with the Antennapedia gene complex of Drosophila melanogaster: Cytology and genetics. Genetics 105: 581-600.

Hodgkin, J., T. Doniach, and M. Shen. 1985. The sex determination pathway in the nematode Caenorhabditis elegans: Variations on a theme. Cold Spring Harbor Symp. Quant. Biol. 50: 585-593.

Kalfayan, L. and P. Wensink. 1981. $\alpha$-tubulin genes of Drosophila. Cell 24: 97-106.

Kaufman, T.C., R. Lewis, and B. Wakimoto. 1980. Cytogenetic analysis of chromosome 3 in Drosophila melanogaster: The homeotic gene complex in polytene chromosome interval 84A,B. Genetics 94: 115-133.

Kuner, J.M., M. Nakanishi, Z. Ali, B. Dress, E. Gustavson, J. Thies, L. Kauvar, T. Kornberg, and P. O'Farrell. 1985. Molecular cloning of engrailed: A gene involved in the development of pattern in Drosophila melanogaster. Cell 42: 309316.

Lawrence, P.A. and P. Johnson. 1986. The muscle pattern of a segment of Drosophila may be determined by neurons and not by contributing myoblasts. Cell 45: 505-513.

Lewis, E.B. 1978. A gene complex controlling segmentation Drosophila melanogaster. Nature 276: 565-570.

Lewis, R.A., T.C. Kaufman, R.E. Denell, and P. Tallerico. 1980. Genetic analysis of the Antennapedia gene complex (Ant-C) and adjacent chromosomal regions of Drosophila melanogaster. I. Polytene chromosome segment 84B-D. Genetics 95: 367-381.

Lindsley, D.L. and E.H. Grell. 1968. Genetic variations of Drosophila melanogaster. Carnegie Inst. Wash. Publ. 627.

Lucchesi, J.C. and T. Skripsky. 1981. The link between dosage compensation and sex differentiation in Drosophila melanogaster. Chromosoma 82: 217-227.

Maine, E.M., H.K. Salz, P. Schedl, and T.W. Cline. 1985a. The Sex-lethal gene of Drosophila: DNA alterations associated with sex-specific lethal mutations. Cell 43: 521-529.

- 1985b. Sex-lethal, a link between sex determination and sexual differentiation in Drosophila melanogaster. Cold Spring Harbor Symp. Quant. Biol. 50: 595-604.

Maniatis, T., E.F. Fritsch, and J. Sambrook. 1982. Molecular cloning: A laboratory manual. Cold Spring Harbor Laboratory, Cold Spring Harbor, New York.

Maniatis, T., R.C. Hardison, E. Lacy, J. Lauer, C. O'Connell, D. Quon, G.K. Sim, and A. Estratiadis. 1978. The isolation of structural genes from libraries of eukaryotic DNA. Cell 15: $687-701$.

Maroni, G. and W. Plaut. 1973. Dosage compensation in Drosophila melanogaster triploids: Autoradiographic study. Chromosoma 40: 361-377.

McKeown, M., J.M. Belote, D.M. Andrew, T.N. Scott, M.F. Wolfner, and B.S. Baker. 1986. Molecular genetics of sex determination in Drosophila. In Gametogenesis and the early embryo. (ed. J.G. Gall) Society for Developmental Biology Symposium 44: 3-17.

McKeown, M., J. Belote, and B.S. Baker. 1987. A molecular analysis of transformer, a gene in Drosophila melanogaster that controls female sexual differentiation. Cell 48: 479-487.

Mischke, D. and M.L. Pardue. 1982. Organization and expression of $\alpha$-tubulin genes in Drosophila melanogaster. One member of the $\alpha$-tubulin gene family is transcribed in both 
oogenesis and later embryonic development. I. Mol. Biol. 150: 449-466.

Murray, N. 1983. In Phage lambda and molecular cloning II. pp. 395-432 Cold Spring Harbor Laboratory, Cold Spring Harbor, New York.

Nagoshi, R.N., M. McKeown, K. Burtis, J.M. Belote, and B.S. Baker. 1988. The control of alternative splicing at genes regulating sexual differentiation in Drosophila melanogaster Cell (in press).

Nasmyth, K.A. 1982. Molecular genetics of yeast mating type Annu. Rev. Genet. 16: 439-500.

Nöthiger, R. and M. Steinmann-Zwicky. 1985. Sex determination in Drosophila. Trends Genet. 1: 209-215.

Ouweneel, W.J. 1976. Developmental genetics of homoeosis. Avd. Genet. 18: 179-248.

Poole, S.J., L.M. Kauvar, B. Drees, and T. Kornberg. 1985. The engrailed locus of Drosophila: Structural analysis of an embryonic transcript. Cell 40: 37-43.

Potter, S.S., M. Truett, M. Philips, and A. Maher. 1980. Eukaryotic transposable genetic elements with inverted terminal repeats. Cell 20: 639-647.

Sanchez, L. and R. Nöthiger. 1982. Clonal analysis of Sexlethal, a gene needed for female sexual development in Drosophila melanogaster. Wilhelm Roux's Arch. Dev. Biol. 191: $211-214$

-1983. Sex determination and dosage compensation in Drosophila: Production of male clones in XX females. EMBO I. 2: 485-491.

Schüpbach, T. 1985. Normal female germ cell differentiation requires the female $\mathrm{X}$-chromosome-autosome ratio and expression of Sex-lethal in Drosophila melanogaster. Genetics 109: 529-548.

Scott, M.P., A.J. Weiner, T.I. Hazelrigg, B.A. Polisky, V. Pirrotta, F. Scalenghe, and T.C. Kaufman. 1983. The molecular organization of the Antennapedia locus of Drosophila. Cell 35: $763-776$.

Steinmann-Zwicky, M. and R. Nöthiger. 1985. A small region on the $\mathrm{X}$ chromosome of Drosophila regulates a key gene that controls sex determination and dosage compensation. Cell 42: 877-887.

Thomas, P.S. 1980. Hybridization of denatured RNA and small DNA fragments transferred to nitrocellulose. Proc. Natl. Acad. Sci. 77: 5201-5205.

Wieschaus, E. and R. Nöthiger. 1982. The role of the transformer genes in the development of the genitalia and analia of Drosophila melanogaster. Dev. Biol. 90: 320-334.

Williams, B.G. and F.R. Blattner. 1979. Construction and characterization of the hybrid bacteriophage lambda Charon vectors for DNA cloning. I. Virol. 29: 555-575. 


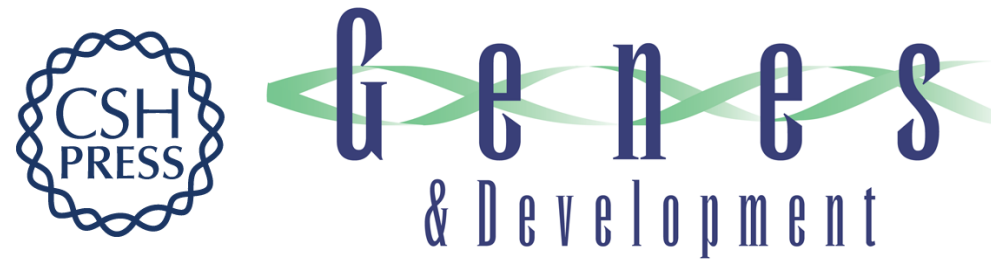

\section{A molecular analysis of doublesex, a bifunctional gene that controls both male and female sexual differentiation in Drosophila melanogaster.}

B S Baker and M F Wolfner

Genes Dev. 1988, 2:

Access the most recent version at doi:10.1101/gad.2.4.477

References This article cites 43 articles, 15 of which can be accessed free at: http://genesdev.cshlp.org/content/2/4/477.full.html\#ref-list-1

License

Email Alerting Service

Receive free email alerts when new articles cite this article - sign up in the box at the top right corner of the article or click here.

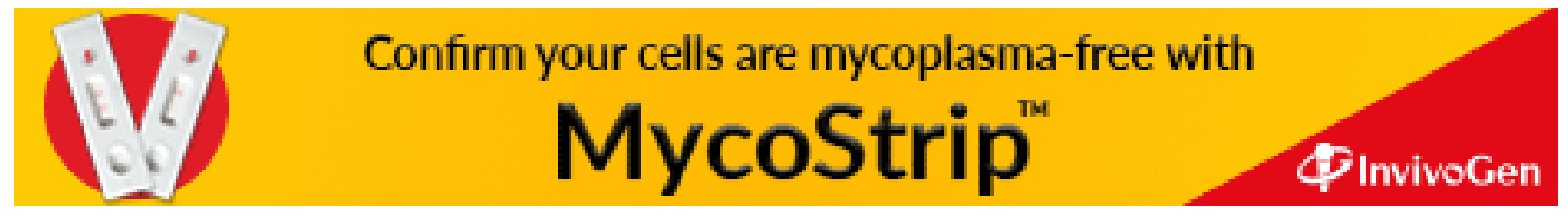

